\title{
Enhanced External Counterpulsation Efficacy on Exercise Endurance in COPD Patients and Healthy Subjects: A Pilot Randomized Clinical Trial
}

This article was published in the following Dove Press journal: International Journal of Chronic Obstructive Pulmonary Disease

\author{
Mingming Zhao, ${ }^{1,2, *}$ \\ Yanqun Huang, ',* Lian Li, ' \\ Ling Zhou,' Zhixin Wu, ${ }^{3}$ \\ Yujun Liu,' Haozhe Zhang,' \\ Caiyou $\mathrm{Hu}^{\prime}$ \\ 'Department of Sports Medicine and \\ Cardiopulmonary Rehabilitation Center, \\ Jiangbin Hospital, Nanning, Guangxi, \\ 53002I, People's Republic of China; \\ ${ }^{2}$ Physical Fitness Surveillance and Health \\ Management Association, Nanning, \\ Guangxi, 53002I, People's Republic of \\ China; ${ }^{3}$ Department of Intensive \\ Medicine, Foshan Hospital of Traditional \\ Chinese Medicine, Foshan 528000, \\ People's Republic of China
}

*These authors contributed equally to this work
Correspondence: Mingming Zhao; Caiyou $\mathrm{Hu}$

Department of Sports Medicine and Cardiopulmonary Rehabilitation Center, Jiangbin Hospital, Nanning, Guangxi

53002I, People's Republic of China

Tel +86077 12080038

Fax +86077 I2080088

Email topabigale@l63.com;

Caiyou.hul33@gmail.com
Purpose: Enhanced external counterpulsation (EECP) is popular in China for the treatment of coronary heart diseases, but it may be an effective treatment for other populations. This study aimed to explore the effect of EECP on exercise endurance of healthy people and chronic obstructive pulmonary disease (COPD) patients and provide intervention measures to improve their physical condition.

Patients and methods: Patients were enrolled in this pilot randomized controlled trial at Jiangbin Hospital, China, between March 1st and May 30th, 2018. They were randomly divided into the EECP and non-EECP groups. According to their maximal oxygen uptake, the volunteers were also sub-grouped into the normal, low exercise endurance, and COPD subgroups. Differences in exercise endurance were evaluated between the EECP and non-EECP groups before and after treatment. Cardiopulmonary exercise testng included anaerobic threshold oxygen uptake $\left(\mathrm{AT}-\mathrm{VO}_{2} \mathrm{Kg}\right)$, maximum oxygen uptake $\left(\mathrm{Max}-\mathrm{VO}_{2} \mathrm{Kg}\right)$, anaerobic threshold pulse (AT-O 2 puls), anaerobic threshold metabolic equivalent (AT-Mets), and maximum metabolic equivalent (Max-Mets).

Results: 72 volunteers were enrolled. The EECP and non-EECP groups were similar in terms of age, sex, body mass index, blood pressure, heart rate, breathing frequency, AT- $\mathrm{VO}_{2}$ $\mathrm{Kg}$, Max- $-\mathrm{VO}_{2} \mathrm{Kg}$, AT- $\mathrm{O}_{2}$ puls, AT-Mets, and Max-Mets $(\mathrm{P}>0.05)$ before treatment. EECP significantly improved AT- $\mathrm{VO}_{2} \mathrm{Kg}, \mathrm{Max}-\mathrm{VO}_{2} \mathrm{Kg}$, AT-O 2 puls, AT-Mets, and Max-Mets compared with the non-EECP group $(\mathrm{P}<0.05)$. When analyzed according to sub-groups, the AT$\mathrm{VO}_{2} \mathrm{Kg}$, Max- $\mathrm{VO}_{2} \mathrm{Kg}$, AT- $\mathrm{O}_{2}$ puls, AT-Mets, and Max-Mets of the normal, low exercise endurance, and COPD subgroups were all significantly increased after EECP $(\mathrm{P}<0.05)$.

Conclusion: EECP significantly improved the exercise endurance of normal adults, low endurance adults, and COPD patients.

Registration number: ChiCTR1900021993.

Keywords: enhanced external counterpulsation, healthy volunteers, exercise tolerance, chronic obstructive pulmonary disease

\section{Introduction}

Sports ability is the ability to participate in sports and training, which is closely related to the comprehensive functions of the heart, brain, lung, skeletal muscle, and endocrine systems. ${ }^{1}$ Sports ability can objectively reflect the overall function of the body and is a powerful predictor of death, even for healthy people with low exercise ability. ${ }^{2}$ Therefore, exercise is of great significance to improve physical condition, enhance resistance of disease, and prolong life. ${ }^{3}$ 
Enhanced external counterpulsation (EECP) is an effective method for the treatment of coronary heart disease and is used widely in China. ${ }^{4}$ It is a safe and effective non-invasive mechanical auxiliary circulation method. ${ }^{5}$ The technique mainly consists of three sets of airbags wrapped around the calf, thigh, and buttocks. EECP consists of applying intermittent positive pressure to the lower body, with this pressure being synchronized with the subject's cardiac cycle, i.e., being sequentially applied distally to proximally at early diastole, and released at the end of diastole. The airbag is pumped up from the lower legs, thighs, and buttocks, which triggers an electrocardiogram (ECG) $\mathrm{R}$ wave, by squeezing the arteriovenous system of the lower half of the body. ${ }^{6}$ By pressing the lower body arterial system, the arterial blood flows to the upper body of the body, which can improve the blood perfusion of vital organs such as the heart and brain. Moreover, by pressing the lower body vein system, the venous reflux of the right heart is increased, and cardiac output is increased through the Frank-Starling mechanism., Recent studies showed that EECP could significantly improve myocardial blood supply, ${ }^{9,10}$ and it may have a role in improving exercise endurance. ${ }^{11}$ This mechanism is different from that of BFRE, which induces hypoxia in the extremities by restricting the returned blood volume, increasing the tolerability of muscles to hypoxia. ${ }^{12}$ EECP is documented in the Expert Consensus and Guidelines for Cardiac Rehabilitation in China as an effective method for the treatment of chronic heart failure, and coronary heart diseases. ${ }^{13}$ EECP has the EC and FDA approvals.

Most studies of EECP involve patients with cardiovascular disease and have only undertaken a superficial investigation into exercise endurance. Other populations may benefit from receiving EECP, including healthy adults and those with chronic obstructive pulmonary disease (COPD). COPD is a common chronic respiratory disorder with airflow limitation and increased inflammatory response in the airways, and it is currently a massive global burden. ${ }^{14}$ Recurrent COPD attacks can lead to increased pulmonary arterial pressure, resulting in increased right atrial load and progression to pulmonary heart disease. ${ }^{15}$ Although the clinical symptoms of patients are relieved after an acute episode, pulmonary function continues to deteriorate, exercise endurance is significantly reduced, and the patient's quality of life is seriously affected. ${ }^{16}$

We hypothesized that EECP might be able to improve the exercise endurance of different groups of adults and might improve the physical condition and the prognosis of patients with COPD. Therefore, the aim of this study was to evaluate whether EECP could improve exercise endurance of healthy adults and those with COPD.

\section{Materials and Methods Subjects}

The volunteers were enrolled at the Cardiopulmonary Rehabilitation Center of Jiangbin Hospital (China) from March 1st to May 30th, 2018. Inclusion criteria: 1) aged $\geq 18$ years old; 2) healthy people and patients diagnosed with COPD but no acute attack according to the Global Strategy for the Diagnosis, Management, and Prevention of Chronic Obstructive Lung Disease 2017 guidelines; ${ }^{17}$ and 3) no operation and injury history. The subjects were excluded from the study if they had heart disease, cerebral disease, pneumonia, liver and kidney disease, neurological diseases, or other infections. As per the device's indications, individuals with blood pressure $\geq 160 / 90 \mathrm{mmHg}$ were excluded.

This preliminary randomized controlled trial was approved by the institutional review board of Jiangbin Hospital. Written informed consent was obtained from all the patients. The study was registered (ChiCTR1900021993).

\section{Randomization, Subgroup, and Intervention}

The subjects were randomized (1:1) into the EECP group and non-EECP group using a random number table. According to the maximal oxygen uptake $\left(\mathrm{VO}_{2} \mathrm{max}\right)$ of cardiopulmonary exercise testing (CPET), the subjects were also divided into subgroups as follows: normal subgroup $\left(\mathrm{VO}_{2} \max \geq 84 \%\right.$ prediction of $\left.\mathrm{VO}_{2} \max \right)$, low exercise endurance subgroup $\left(\mathrm{VO}_{2} \max <84 \%\right.$ prediction of $\mathrm{VO}_{2} \max$ ), and COPD subgroup.

The EECP equipment (P-ECP/TI, Chongqing PSKhealth Sci-Tech Development Co.,Ltd , China) consisted of an ECG monitor and air compressor that could cover two legs and the hip. Before the treatment began, the air compressor cuffs were wrapped around the subject's limbs. The primary cuff was empty without pressure. When EECP therapy began, a sequence of synchronized pressure was given according to the cardiac cycle. In early ventricular diastole, the compressor increased the pressure of the cuffs in sequence from the lower legs to the upper legs and the hips. This regular succession improved the arterial blood pressure and blood flow during the diastolic period. At the end of the diastole, 
the air in the cuff was released promptly, which reduced vascular impedance. According to the instruction manual, the maximal cuff pressure was set as $0.03 \mathrm{mPa}$. An experienced and trained physician operated the equipment in this study. All subjects in the EECP group underwent EECP therapy for $1 \mathrm{hr} /$ day, 5 days/week, for 3 weeks, and the non-EECP group did not.

\section{Assessment}

The German Cortex CPET system (CPX International, Germany) was used to test the anaerobic threshold of the subjects during exercise. The measurements included anaerobic threshold oxygen uptake $\left(\mathrm{AT}-\mathrm{VO}_{2} \mathrm{Kg}\right)$, maximum oxygen uptake $\left(\mathrm{Max}-\mathrm{VO}_{2} \mathrm{Kg}\right)$, anaerobic threshold pulse (AT- $\mathrm{O}_{2}$ puls), anaerobic threshold training load (ATLoad), anaerobic threshold metabolic equivalent (ATMets), and maximum metabolic equivalent (Max-Mets).

Symptom-limited cardiopulmonary exercise testing (CPET) on a bike was performed at baseline (the day before EECP treatment) and on the day after EECP treatment finished. Testing was terminated if there was the onset of angina pain, dizziness, dyspnea, or arrhythmia on 12-lead electric-cardiogram (ECG), or reluctance of the subject to continue the exercise testing.

Safety was assessed through adverse event monitoring such as skin damage, chest tightness, muscular pain, embolism, etc.

\section{Statistical Analysis}

The full analysis set (all randomized participants who received at least one treatment and had at least one postbaseline efficacy assessment) and safety set (all randomized participants who received at least one treatment and had at least one post-baseline safety assessment) were used for analysis. All statistical analyses were performed using SPSS Statistics 17 for Windows (IBM, Armonk, NY, USA). Continuous variables are expressed as means \pm standard deviations (SD). Comparisons between the EECP and non-EECP groups were made with the independent $t$-test. The paired $t$-test was used for comparison before and after EECP treatment. Categorical variables are expressed as numbers (percentages). Comparisons were made using the chi-square or Fisher's extract test. The analyzed effects were the differences before and after the treatment and the corresponding P-value and $95 \%$ CIs. $P<0.05$ was stipulated for statistical significance.

\section{Results}

Eighty-two volunteers were eligible. Six volunteers withdrew their consent. One was lost to follow-up. Three discontinued intervention because of acute exacerbations of COPD $(n=2)$ and burn injury $(n=1)$. Finally, there were 39 males and 33 females, aged 27-82 years. They were divided into the EECP group ( $\mathrm{n}=37$, aged $57.30 \pm 21.16$ years) and the non-EECP group ( $n=35$, aged $54.23 \pm 23.37$ years) (Figure $S 1$ ). For the EECP group, there were 11,13 , and 13 volunteers in the normal, low exercise endurance, and COPD subgroups, respectively. For the non-EECP group, there were 15, 10, and 10 volunteers in the normal, low exercise endurance, and COPD subgroups, respectively.

The EECP and non-EECP groups were similar in terms of age, gender, body mass index (BMI), blood pressure, heart rate, breathing frequency, $\mathrm{AT}-\mathrm{VO}_{2} \mathrm{Kg}, \mathrm{Max}-\mathrm{VO}_{2} \mathrm{Kg}$, AT- $\mathrm{O}_{2}$ puls, AT-Mets, and Max-Mets $(\mathrm{P}>0.05)$ before treatment, as shown in Table $\mathrm{S} 1$.

\section{Comparison of Exercise Endurance}

There were no statistically significant differences between the two groups before treatment in anaerobic threshold heart rate (AT-HR), anaerobic threshold inter-beat interval (AT-RR), anaerobic threshold systolic blood pressure (AT-SBP), anaerobic threshold diastolic blood pressure (AT-DBP), maximum systolic blood pressure (Max-SBP), maximum diastolic blood pressure (Max-DBP), AT- $\mathrm{VO}_{2} \mathrm{Kg}, \mathrm{Max}-\mathrm{VO}_{2} \mathrm{Kg}$, AT-O ${ }_{2}$ puls, and Max-Mets (all $\mathrm{P}>0.05$ ); the same was found after EECP treatment $(\mathrm{P}>0.05)$. When the two groups were compared after treatment, there were significant differences of $\mathrm{AT}-\mathrm{VO}_{2} \mathrm{Kg}$, Max- $-\mathrm{VO}_{2} \mathrm{Kg}$, AT-O 2 puls, AT-Load, AT-Mets, and Max-Mets between the EECP and non-EECP groups (all $\mathrm{P}<0.05$ ) (Table S2).

Table I Comparison of General Data Between the Treatment Groups in the Normal Subgroup

\begin{tabular}{|l|l|l|l|}
\hline & $\begin{array}{l}\text { EECP Group } \\
(\mathbf{n}=\mathrm{II})\end{array}$ & $\begin{array}{l}\text { Non-EECP Group } \\
(\mathbf{n}=\mathbf{I 5})\end{array}$ & $\mathbf{P}$ \\
\hline Age (years) & $35.64 \pm 20.33$ & $35.73 \pm 21.92$ & 0.991 \\
Sex, male (\%) & $2(18.2 \%)$ & $4(26.7 \%)$ & 0.612 \\
BMI (kg/m²) & $23.75 \pm 4.96$ & $24.44 \pm 2.44$ & 0.378 \\
SBP (mmHg) & $120.73 \pm 10.27$ & $122.40 \pm 12.25$ & 0.716 \\
DBP (mmHg) & $72.36 \pm 7.13$ & $72.73 \pm 10.36$ & 0.920 \\
HR (bpm) & $78.72 \pm 4.96$ & $79.00 \pm 5.76$ & 0.901 \\
RR (bpm*) & $18.09 \pm 2.12$ & $18.53 \pm 2.20$ & 0.610 \\
\hline
\end{tabular}

Abbreviations: EECP, enhanced external counterpulsation; BMI, body mass index; SBP, systolic blood pressure; DBP, diastolic blood pressure; HR, heart rate; RR, respiratory rate; bpm, beats per minute, bpm*, breaths per minute. 
Table 2 Comparison of Exercise Endurance Between the Two Groups in the Normal Subgroup

\begin{tabular}{|c|c|c|c|c|c|c|c|c|}
\hline \multirow[t]{2}{*}{ Parameter } & \multicolumn{3}{|c|}{ EECP Group $(n=I I)$} & \multicolumn{3}{|c|}{ Non-EECP Group $(n=15)$} & \multirow[t]{2}{*}{ P-value } & \multirow[t]{2}{*}{$95 \% \mathrm{Cl}$} \\
\hline & Before & After & $\Delta$ (After-Before) & Before & After & $\Delta$ (After-Before) & & \\
\hline ATHR (bpm) & $118.27 \pm 10.88$ & $115.09 \pm 7.23$ & $-3.18 \pm 5.74$ & $1 \mid 3.67 \pm 15.53$ & $116.87 \pm 15.33$ & $3.2 \pm 1.86$ & 0.000 & $-9.633,-3.130$ \\
\hline ATRR (bpm*) & $25.18 \pm 3.25$ & $24.64 \pm 2.66$ & $-0.55 \pm 2.34$ & $24.20+3.86$ & $25.93 \pm 3.90$ & $1.73 \pm 1.58$ & 0.007 & $-3.862,-0.695$ \\
\hline ATSBP $(\mathrm{mmHg})$ & $130.91 \pm 21.66$ & $129.27 \pm 22.46$ & $-1.64 \pm 4.4 \mid$ & $132.73 \pm 14.94$ & $|34.07 \pm| 3.6 \mid$ & $1.33 \pm 4.45$ & 0.105 & $-6.603,0.663$ \\
\hline ATDBP $(\mathrm{mmHg})$ & $68.91 \pm 11.57$ & $69.18 \pm 11.14$ & $0.27 \pm 4.24$ & $74.80 \pm 8.04$ & $77.20 \pm 7.25$ & $2.40 \pm 2.80$ & 0.136 & $-4.974,0.719$ \\
\hline Max SBP (mmHg) & $161.18 \pm 26.97$ & $162.91 \pm 26.50$ & $1.73 \pm 3.93$ & $155.93 \pm 20.10$ & $159.73 \pm 20.17$ & $3.80 \pm 2.81$ & 0.129 & $-4.793,0.648$ \\
\hline $\operatorname{Max} \mathrm{DBP}(\mathrm{mmHg})$ & $78.45 \pm 17.32$ & $80.00 \pm 16.06$ & $1.55 \pm 4.20$ & $85.47 \pm 12.28$ & $88.93 \pm 11.97$ & $3.47 \pm 3.18$ & 0.196 & $-4.906,1.063$ \\
\hline $\mathrm{ATVO}_{2} \mathrm{Kg}(\mathrm{mL} / \mathrm{min} \cdot \mathrm{kg})$ & $|4.00 \pm 3.4|$ & $15.64 \pm 3.64$ & $1.64 \pm 0.67$ & $14.67 \pm 5.70$ & $14.32 \pm 5.50$ & $-0.33 \pm 0.49$ & 0.000 & $1.500,2.439$ \\
\hline $\mathrm{MaxVO}_{2} \mathrm{Kg}(\mathrm{mL} / \mathrm{min} \cdot \mathrm{kg})$ & $23.91 \pm 6.09$ & $26.18 \pm 5.76$ & $2.27 \pm 1.10$ & $24.53 \pm 8.43$ & $23.87 \pm 8.24$ & $-0.47 \pm 0.49$ & 0.000 & $2.281,3.598$ \\
\hline ATVO $_{2}$ puls $(\mathrm{mL})$ & $6.55 \pm 1.51$ & $7.36 \pm 1.57$ & $0.82 \pm 0.60$ & $7.53+3.00$ & $8.07 \pm 3.81$ & $0.53 \pm 2.39$ & 0.704 & $-1.242,1.812$ \\
\hline ATLoad (watt) & $66.27 \pm 16.53$ & $73.55 \pm 16.00$ & $7.27 \pm 0.29$ & $68.60 \pm 24.20$ & $66.47 \pm 24.22$ & $-2.13 \pm 2.61$ & 0.000 & $6.608,12.20$ \\
\hline ATMets & $4.54 \pm 0.89$ & $5.15 \pm 1.26$ & $0.61 \pm 0.70$ & $4.51 \pm 1.54$ & $4.43 \pm 1.52$ & $-0.09 \pm 0.15$ & 0.001 & $0.312,1.080$ \\
\hline MaxMets & $7.43 \pm 1.74$ & $8.01 \pm 1.75$ & $0.58 \pm 0.42$ & $7.44 \pm 2.63$ & $7.32 \pm 2.58$ & $-0.11 \pm 0.16$ & 0.000 & $0.452,0.938$ \\
\hline
\end{tabular}

Abbreviations: EECP, enhanced external counterpulsation; AT, anaerobic threshold; HR, heart rate; RR, respiratory rate; bpm, beats per minute; bpm*, breaths per minute; $\mathrm{SBP}$, systolic blood pressure; DBP, diastolic blood pressure; $\mathrm{VO}_{2}$, oxygen uptake; Mets, metabolic equivalent.

\section{Subgroup Analysis}

\section{Comparison of Exercise Endurance in the Normal Population Subgroup}

There were no statistically significant differences between the two groups (EECP group, $\mathrm{n}=11$; non-EECP group, $\mathrm{n}=15$ ) before treatment in terms of AT-HR, AT-RR, AT-SBP, ATDBP, Max-SBP, Max-DBP, AT- $\mathrm{VO}_{2} \mathrm{Kg}, \mathrm{Max}_{-} \mathrm{VO}_{2} \mathrm{Kg}$, AT- $\mathrm{O}_{2}$ puls, AT- $\mathrm{O}_{2}$ puls, and Max-Mets (all $\mathrm{P}>0.05$ ); the same was found after EECP treatment (all $\mathrm{P}>0.05$ ). When the two groups were compared before and after treatment, AT- $\mathrm{VO}_{2}$ $\mathrm{Kg}, \mathrm{Max}-\mathrm{VO}_{2} \mathrm{Kg}$, AT-O ${ }_{2}$ puls, AT-Load, AT-Mets, and MaxMets were all more significantly improved in the EECP group than in the non-EECP group (all $\mathrm{P}<0.05$ ) (Tables 1 and 2).

\section{Comparison of Exercise Endurance in the Low Exercise Endurance Subgroup}

There were no statistically significant differences between the two groups before treatment in AT-HR, AT-RR, ATSBP, AT-DBP, Max-SBP, Max-DBP, AT- $\mathrm{VO}_{2} \mathrm{Kg}$, Max$\mathrm{VO}_{2} \mathrm{Kg}$, AT- $\mathrm{O}_{2}$ puls, and Max-Mets (all $\mathrm{P}>0.05$ ); the same was found after EECP treatment (all $\mathrm{P}>0.05$ ). When the two groups were compared before and after treatment, AT- $\mathrm{VO}_{2} \mathrm{Kg}, \quad \mathrm{Max}-\mathrm{VO}_{2} \mathrm{Kg}, \mathrm{AT}-\mathrm{O}_{2}$ puls, ATLoad, AT-Mets, and Max-Mets were all more significantly improved in the EECP group compared with the nonEECP group (all $\mathrm{P}<0.05$ ) (Tables 3 and 4).

\section{Comparison of Exercise Endurance in the COPD Subgroup}

There were no statistically significant differences between the two groups before treatment in AT-HR, AT-RR, ATSBP, AT-DBP, Max-SBP, Max-DBP, AT- $\mathrm{VO}_{2} \mathrm{Kg}$, Max-
Table 3 Comparison of General Data Between the Groups in the Low Exercise Endurance Subgroup

\begin{tabular}{|l|l|l|l|}
\hline & $\begin{array}{l}\text { EECP Group } \\
(\mathbf{n}=13)\end{array}$ & $\begin{array}{l}\text { Non-EECP Group } \\
(\mathbf{n}=1 \mathbf{0})\end{array}$ & $\mathbf{P}$ \\
\hline Age (years) & $59.92 \pm 15.50$ & $57.70 \pm 3.59$ & 0.663 \\
Sex, male (\%) & $9(69.2)$ & $5(50.0 \%)$ & 0.349 \\
BMI $\left(\mathrm{kg} / \mathrm{m}^{2}\right)$ & $26.42 \pm 4.47$ & $26.96 \pm 5.58$ & 0.799 \\
SBP $(\mathrm{mmHg})$ & $120.31 \pm 11.95$ & $119.80 \pm 8.94$ & 0.912 \\
DBP $(\mathrm{mmHg})$ & $72.85 \pm 9.48$ & $75.90 \pm 8.25$ & 0.377 \\
HR (bpm) & $79.69 \pm 5.1$ & $79.10 \pm 5.22$ & 0.788 \\
RR (bpm*) & $18.23 \pm 1.96$ & $18.00 \pm 2.36$ & 0.800 \\
\hline
\end{tabular}

Abbreviations: EECP, enhanced external counterpulsation; BMI, body mass index; SBP, systolic blood pressure; DBP, diastolic blood pressure; HR, heart rate; RR, respiratory rate; bpm, beats per minute; bpm*, breaths per minute.

$\mathrm{VO}_{2} \mathrm{Kg}$, AT- $\mathrm{O}_{2}$ puls, and Max-Mets (all $\mathrm{P}>0.05$ ); the same was found after EECP treatment (all $\mathrm{P}>0.05$ ). When the two groups were compared before and after treatment, AT- $\mathrm{VO}_{2} \mathrm{Kg}, \quad \mathrm{Max}-\mathrm{VO}_{2} \mathrm{Kg}, \mathrm{AT}-\mathrm{O}_{2}$ puls, ATLoad, AT-Mets, and Max-Mets were all more significantly improved in the EECP group compared with the nonEECP group (all $\mathrm{P}<0.05$ ) (Tables 5 and 6).

\section{Safety}

No subject had any adverse event in this trial.

\section{Discussion}

The aim of this study was to investigate whether EECP was able to improve the exercise endurance of healthy adults, those with low exercise endurance, and patients with COPD. The results showed that EECP significantly improved AT- $\mathrm{VO}_{2} \mathrm{Kg}, \mathrm{Max}-\mathrm{VO}_{2} \mathrm{Kg}$, AT- $\mathrm{O}_{2}$ puls, AT-Mets, 
Table 4 Comparison of Exercise Endurance Between the Two Groups in the Low Exercise Endurance Subgroup

\begin{tabular}{|c|c|c|c|c|c|c|c|c|}
\hline \multirow[t]{2}{*}{ Parameter } & \multicolumn{3}{|c|}{ EECP Group $(n=13)$} & \multicolumn{3}{|c|}{ Non-EECP Group $(n=10)$} & \multirow[t]{2}{*}{ P-value } & \multirow[t]{2}{*}{$95 \% \mathrm{Cl}$} \\
\hline & Before & After & $\begin{array}{l}\Delta \text { (After- } \\
\text { Before) }\end{array}$ & Before & After & $\begin{array}{l}\Delta \text { (After- } \\
\text { Before) }\end{array}$ & & \\
\hline ATHR (bpm) & $99.62 \pm 14.34$ & $102.82 \pm 14.65$ & $3.23 \pm 2.01$ & $100.60 \pm 11.43$ & $104.30 \pm 11.99$ & $3.70 \pm 1.64$ & 0.554 & $-2.093,1.155$ \\
\hline ATRR (bpm*) & $23.46 \pm 3.83$ & $24.38 \pm 3.89$ & $0.92 \pm 0.95$ & $22.20+4.08$ & $24.40 \pm 3.17$ & $2.20 \pm 1.62$ & 0.028 & $-2.398,-0.155$ \\
\hline ATSBP $(\mathrm{mmHg})$ & $142.23 \pm 23.85$ & $144.08 \pm 22.28$ & $1.85 \pm 3.24$ & $148.70 \pm 14.10$ & $148.10 \pm 13.44$ & $-0.60 \pm 4.53$ & 0.145 & $-0.915,5.807$ \\
\hline ATDBP $(\mathrm{mmHg})$ & $77.85 \pm \mid 4.11$ & $77.31 \pm 10.56$ & $-0.54 \pm 4.35$ & $83.40 \pm 5.72$ & $86.50 \pm 5.80$ & $3.10 \pm 4.07$ & 0.054 & $-7.340,0.063$ \\
\hline Max SBP (mmHg) & $170.15 \pm 24.49$ & $171.31 \pm 21.20$ & $1.15 \pm 5.32$ & $186.90 \pm 20.09$ & $185.70 \pm 19.95$ & $-1.20 \pm 2.62$ & 0.214 & $-1.469,6.177$ \\
\hline Max DBP $(\mathrm{mmHg})$ & $87.00 \pm 14.05$ & $89.62 \pm 11.63$ & $2.62 \pm 4.64$ & $95.60 \pm 11.63$ & $99.50 \pm 10.40$ & $3.90 \pm 2.64$ & 0.466 & $-4.886,2.316$ \\
\hline ATVO $_{2} \mathrm{Kg}(\mathrm{mL} / \mathrm{min} \cdot \mathrm{kg})$ & $10.85 \pm 2.64$ & $12.69 \pm 3.28$ & $1.85 \pm 0.90$ & $11.40 \pm 2.07$ & $10.60 \pm 1.90$ & $-0.80 \pm 0.42$ & 0.000 & $2.004,3.287$ \\
\hline $\begin{array}{l}\mathrm{MaxVO}_{2} \mathrm{Kg}(\mathrm{mL} / \\
\min \cdot \mathrm{kg})\end{array}$ & $17.38 \pm 6.68$ & $18.38 \pm 6.85$ & $1.00 \pm 0.91$ & $17.00 \pm 1.16$ & $16.00 \pm 1.15$ & $-1.00 \pm 0.00$ & 0.000 & $1.396,2.603$ \\
\hline ATVO $_{2}$ puls (mL) & $9.85 \pm 7.93$ & $10.92 \pm 8.30$ & $1.08 \pm 0.76$ & $7.90+1.91$ & $7.40 \pm 1.58$ & $-0.50 \pm 0.53$ & 0.000 & $0.990,2.162$ \\
\hline ATLoad (watt) & $50.85 \pm 31.26$ & $55.62 \pm 31.60$ & $4.77 \pm 2.17$ & $52.70 \pm 16.63$ & $50.20 \pm 16.16$ & $-2.50 \pm 2.17$ & 0.000 & $5.371,9.166$ \\
\hline ATMets & $3.45 \pm 1.32$ & $3.75 \pm 1.40$ & $0.31 \pm 0.14$ & $3.35 \pm 0.65$ & $3.38 \pm 0.48$ & $0.03 \pm 0.22$ & 0.001 & $0.121,0.433$ \\
\hline MaxMets & $5.12 \pm 1.85$ & $5.45 \pm 2.06$ & $0.34 \pm 0.38$ & $4.78 \pm 0.83$ & $4.73 \pm 0.78$ & $-0.05 \pm 0.10$ & 0.005 & $0.134,0.643$ \\
\hline
\end{tabular}

Abbreviations: EECP, enhanced external counterpulsation; AT, anaerobic threshold; HR, heart rate; RR, respiratory rate; bpm, beats per minute, bpm*, breaths per minute; $\mathrm{SBP}$, systolic blood pressure; DBP, diastolic blood pressure; $\mathrm{VO}_{2}$, oxygen uptake; Mets, metabolic equivalent.

and Max-Mets in the overall population of this study. When analyzed according to subgroups, the $\mathrm{AT}-\mathrm{VO}_{2} \mathrm{Kg}$, Max- $\mathrm{VO}_{2} \mathrm{Kg}$, AT-O 2 puls, AT-Mets, and Max-Mets of the normal, low exercise endurance, and COPD subgroups were all significantly increased after EECP. Therefore, these results suggest that EECP is likely to improve exercise endurance in different populations of adults.

Study suggests that athletic ability is closely related to the mortality risk, ${ }^{1}$ but previous studies of EECP were focused on patients with coronary heart diseases, ${ }^{18-20}$ and there are relatively few studies on exercise endurance of other populations including normal and healthy people. Peak- $\mathrm{VO}_{2} \mathrm{Kg}$ is the gold standard for the evaluation of cardiopulmonary fitness, $\mathrm{Max}-\mathrm{VO}_{2} \mathrm{Kg}$ is used to evaluate endurance, and AT$\mathrm{VO}_{2} \mathrm{Kg}$ is used in the evaluation of aerobic exercise

Table 5 Comparison of General Data Between the Groups in the COPD Subgroup

\begin{tabular}{|l|l|l|l|}
\hline & $\begin{array}{l}\text { EECP Group } \\
(\mathbf{n}=13)\end{array}$ & $\begin{array}{l}\text { Non-EECP Group } \\
(\mathbf{n}=1 \mathbf{0})\end{array}$ & $\mathbf{P}$ \\
\hline Age (years) & $73.00 \pm 7.33$ & $78.50 \pm 8.09$ & 0.103 \\
Sex, male (\%) & $11(84.6 \%)$ & $8(80.0 \%)$ & 0.772 \\
BMI (kg/m²) & $23.75 \pm 4.96$ & $24.44 \pm 2.44$ & 0.639 \\
SBP (mmHg) & $123.08 \pm 13.44$ & $122.60 \pm 11.06$ & 0.928 \\
DBP (mmHg) & $78.00 \pm 7.90$ & $79.10 \pm 5.22$ & 0.708 \\
HR (bpm) & $76.54 \pm 8.75$ & $80.90 \pm 4.23$ & 0.133 \\
RR (bpm*) & $19.54 \pm 1.61$ & $19.60 \pm 2.55$ & 0.948 \\
\hline
\end{tabular}

Abbreviations: COPD, chronic obstructive pulmonary disease; EECP, enhanced external counterpulsation; BMI, body mass index; SBP, systolic blood pressure; DBP, diastolic blood pressure; HR, heart rate; RR, respiratory rate; bpm, beats per minute; bpm*, breaths per minute. capacity. ${ }^{21}$ The present study showed that exercise endurance evaluation indexes such as AT- $\mathrm{VO}_{2} \mathrm{Kg}, \mathrm{Max}-\mathrm{VO}_{2} \mathrm{Kg}$, AT- $\mathrm{O}_{2}$ puls, AT-Load, AT-Mets, and Max-Mets were improved after EECP therapy in the general population without cardiovascular diseases. This suggests that EECP can generally improve exercise endurance. This is contradicted by another study that was undertaken in 12 elite junior triathletes that looked at the role of EECP in recovery after a high-intensity interval training session (six bouts of 3-mins duration at maximal intensity interspersed with 3 -min rest periods). ${ }^{22}$ In that study, EECP did not enhance short-term recovery, but exercise endurance was not a major endpoint, and the population was very different from the present study. Therefore, the studies are not directly comparable.

According to the differences in condition and exercise capacity of the subjects, we conducted a subgroup analysis of the normal, low exercise endurance, and COPD subgroups. The results showed that after EECP treatment, their exercise endurance was higher than those who were untreated. Furthermore, the increase of diastolic blood pressure in the process of exercise cardiopulmonary test after EECP treatment was lower than before treatment, and this is probably due to the effect of external counterpulsation in regulating blood pressure and heart rate. ${ }^{23,24}$ These changes may be related to the improvement of cardiovascular fitness and cardiac function with EECP therapy. EECP therapy can improve cardiac function and oxygen uptake; ${ }^{25}$ moreover, cardiac function is significantly correlated with exercise capacity. For the normal and low endurance populations, EECP can increase the blood flow and perfusion of the 
Table 6 Comparison of Exercise Endurance Between the Two Groups in the COPD Subgroup

\begin{tabular}{|c|c|c|c|c|c|c|c|c|}
\hline \multirow[t]{2}{*}{ Parameter } & \multicolumn{3}{|c|}{ EECP Group $(n=13)$} & \multicolumn{3}{|c|}{ Non-EECP Group $(n=10)$} & \multirow[t]{2}{*}{ P-value } & \multirow[t]{2}{*}{$95 \% \mathrm{Cl}$} \\
\hline & Before & After & $\Delta$ (After-Before) & Before & After & $\Delta$ (After-Before) & & \\
\hline ATHR (bpm) & $102.77 \pm 17.24$ & $108.62 \pm 16.57$ & $5.85 \pm 5.87$ & $93.10 \pm 15.84$ & $97.40 \pm 15.20$ & $4.30 \pm 1.89$ & 0.434 & $-2.484,5.576$ \\
\hline ATRR (bpm*) & $24.15 \pm 4.90$ & $26.00 \pm 3.83$ & $1.85 \pm 2.30$ & $23.30+3.23$ & $25.50 \pm 3.14$ & $2.20 \pm 0.92$ & 0.653 & $-1.965,1.257$ \\
\hline ATSBP $(\mathrm{mmHg})$ & $147.15 \pm 15.52$ & $151.23 \pm 17.17$ & $4.08 \pm 4.95$ & $|44.90 \pm 8.2|$ & $145.00 \pm 5.77$ & $0.10 \pm 4.19$ & 0.067 & $-0.299,8.252$ \\
\hline ATDBP $(\mathrm{mmHg})$ & $80.54 \pm 15.01$ & $83.00 \pm 14.10$ & $2.46 \pm 3.64$ & $81.00 \pm 3.40$ & $80.40 \pm 5.38$ & $-0.60 \pm 4.12$ & 0.073 & $-0.308,6.431$ \\
\hline $\operatorname{Max} \mathrm{SBP}(\mathrm{mmHg})$ & $169.23 \pm 32.59$ & $169.69 \pm 21.09$ & $0.46 \pm 16.8$ & $170.40 \pm 10.02$ & $171.60 \pm 9.83$ & $1.20 \pm 1.99$ & 0.829 & $-11.88,10.40$ \\
\hline $\operatorname{Max} \mathrm{DBP}(\mathrm{mmHg})$ & $88.08 \pm 19.78$ & $88.46 \pm 13.47$ & $0.38 \pm 12.0$ & $88.00 \pm 14.29$ & $93.70 \pm 9.50$ & $5.70 \pm 8.39$ & 0.247 & $-14.60,3.971$ \\
\hline $\mathrm{ATVO}_{2} \mathrm{Kg}(\mathrm{mL} / \mathrm{min} \cdot \mathrm{kg})$ & $9.77 \pm 2.59$ & $11.38 \pm 2.87$ & $1.62 \pm 1.26$ & $9.30 \pm 2.45$ & $8.70 \pm 2.63$ & $-0.06 \pm 0.52$ & 0.000 & $1.330,3.099$ \\
\hline $\mathrm{MaxVO}_{2} \mathrm{Kg}(\mathrm{mL} / \mathrm{min} \cdot \mathrm{kg})$ & $11.38 \pm 2.82$ & $14.62 \pm 2.22$ & $1.23 \pm 1.24$ & $17.00 \pm 3.94$ & $13.20 \pm 3.94$ & $-0.08 \pm 0.42$ & 0.000 & $1.179,2.882$ \\
\hline ATVO $_{2}$ puls (mL) & $5.92 \pm 1.80$ & $7.31 \pm 1.93$ & $1.38 \pm 0.87$ & $6.80+1.23$ & $6.20 \pm 1.62$ & $-0.06 \pm 0.52$ & 0.000 & $1.337,2.631$ \\
\hline ATLoad (watt) & $35.08 \pm 17.40$ & $41.46 \pm 18.36$ & $6.38 \pm 3.64$ & $42.40 \pm 14.07$ & $41.90 \pm 12.49$ & $-0.05 \pm 4.20$ & 0.000 & $3.482,10.29$ \\
\hline ATMets & $2.90 \pm 0.68$ & $3.32 \pm 0.85$ & $0.42 \pm 0.35$ & $2.83 \pm 0.87$ & $2.74 \pm 0.83$ & $-0.09 \pm 0.14$ & 0.000 & $0.263,0,747$ \\
\hline MaxMets & $3.88 \pm 0.75$ & $4.26 \pm 0.64$ & $0.37 \pm 0.41$ & $4.23 \pm 1.19$ & $4.15 \pm 1.17$ & $-0.08 \pm 0.06$ & 0.002 & $0.183,0.730$ \\
\hline
\end{tabular}

Abbreviations: COPD, chronic obstructive pulmonary disease; EECP, enhanced external counterpulsation; AT, anaerobic threshold; HR, heart rate; RR, respiratory rate; bpm, beats per minute; bpm*, breaths per minute; SBP, systolic blood pressure; DBP, diastolic blood pressure; $\mathrm{VO}_{2}$, oxygen uptake; Mets, metabolic equivalent.

limbs, and strengthen the nutrition of slow and fast muscle fibers. Moreover, one study found that EECP therapy can induce the response of skeletal muscle cells, and increase the expression of IGF-1 and FGF-2 in skeletal muscle tissue, which is closely related to the metabolism of skeletal muscle cells and their ability to increase oxygenation. ${ }^{18}$

In patients with COPD, the present study showed that EECP therapy could also improve exercise endurance in this population. Although the pulmonary function was not determined in this group, a small sample study showed improvement of pulmonary function in patients with COPD and improvement of their 6-mins walking distance with EECP. ${ }^{26}$ In theory, EECP can improve blood rheology, microcirculation, visceral tissue perfusion, blood flow to the lungs, and pulmonary ventilation/blood flow ratio, thus improving pulmonary oxygenation function. ${ }^{27,28}$

Therefore, taken together, the results suggest that EECP could improve the cardiopulmonary functions of healthy adults and those with lower physical condition. In addition, even patients with a disease known to limit the physical condition severely may benefit from EECP. Considering that this intervention is non-invasive and is relatively inexpensive, it is worth popularization. The exact mechanisms by which EECP improves the cardiopulmonary functions still need to be determined, as well as the populations of individuals who may benefit the most from EECP.

This study has some limitations. The sample size was small, and the follow-up time was short. Therefore, the subgroup analyses must be considered as bases for future studies. Finally, stratified randomization was not used. The results need to be confirmed using a large-scale multicenter clinical trial.

\section{Conclusion}

In conclusion, this pilot study suggests that EECP leads to a certain improvement effect on the exercise endurance of different adult populations, from healthy adults to those with COPD. Whether EECP can improve exercise tolerance of other diseases needs further study.

\section{Ethics Approval and Informed Consent}

This trial was conducted in accordance with the Declaration of Helsinki, and this preliminary randomized controlled trial was approved by the institutional review board of Jiangbin Hospital. Written informed consent was obtained from all the patients. The study was registered (ChiCTR1900021993).

\section{Data Sharing Statement}

The datasets used and/or analyzed during the current study are available from the corresponding author on reasonable request.

\section{Funding}

This study was funded by the Project for Guangxi Medical and Health Technologies (Grant Number: S2018116), Guangxi Health Commission Project (Grant Numbers: Z20190770, Z20190766), Science and Technology Foundation of Foshan City, China (Grant Number: 2017AG100061). 


\section{Disclosure}

The authors report no conflicts of interest in this work.

\section{References}

1. Vina J, Sanchis-Gomar F, Martinez-Bello V, Gomez-Cabrera MC. Exercise acts as a drug; the pharmacological benefits of exercise. $\mathrm{Br}$ J Pharmacol. 2012;167(1):1-12. doi:10.1111/j.1476-5381.2012.01970.x

2. Myers J, Prakash M, Froelicher V, Do D, Partington S, Atwood JE. Exercise capacity and mortality among men referred for exercise testing. N Engl J Med. 2002;346(11):793-801. doi:10.1056/NEJMoa011858

3. Bouaziz W, Lang PO, Schmitt E, Kaltenbach G, Geny B, Vogel T. Health benefits of multicomponent training programmes in seniors: a systematic review. Int $J$ Clin Pract. 2016;70(7):520-536. doi:10.1111/ijcp.12822

4. Qin X, Deng Y, Wu D, Yu L, Huang R. Does enhanced external counterpulsation (EECP) significantly affect myocardial perfusion? A systematic review \& meta-analysis. PLoS One. 2016;11(4): e0151822. doi:10.1371/journal.pone.0151822

5. Raza A, Steinberg K, Tartaglia J, Frishman WH, Gupta T. Enhanced external counterpulsation therapy: past, present, and future. Cardiol Rev. 2017;25(2):59-67. doi:10.1097/CRD.0000000000000122

6. Sharma U, Ramsey HK, Tak T. The role of enhanced external counter pulsation therapy in clinical practice. Clin Med Res. 2013;11 (4):226-232. doi:10.3121/cmr.2013.1169

7. Soroff HS, Hui JCK, Giron F. Historical review of the development of enhanced external counterpulsation technology and its physiologic rationale. Cardiovasc Rev Rep. 1997;18:28-32.

8. Arora RR, Chou TM, Jain D, et al. The multicenter study of enhanced external counterpulsation (MUST-EECP): effect of EECP on exercise-induced myocardial ischemia and anginal episodes. $J$ Am Coll Cardiol. 1999;33(7):1833-1840. doi:10.1016/S0735-1097(99)00140-0

9. Nichols WW, Estrada JC, Braith RW, Owens K, Conti CR. Enhanced external counterpulsation treatment improves arterial wall properties and wave reflection characteristics in patients with refractory angina. $J \mathrm{Am}$ Coll Cardiol. 2006;48(6):1208-1214. doi:10.1016/j.jacc.2006.04.094

10. Enhanced External Counterpulsation (EECP). An evidence-based analysis. Ont Health Technol Assess Ser. 2006;6(5):1-70.

11. May O, Lynggaard V, Mortensen JC, Malczynski J. Enhanced external counterpulsation - effect on angina pectoris, QoL and exercise capacity after 1 year. Scand Cardiovasc J. 2015;49(1):1-6.

12. Patterson SD, Hughes L, Warmington S, et al. Blood flow restriction exercise position stand: considerations of methodology, application, and safety. Front Physiol. 2019;10:533. doi:10.3389/fphys.2019.00533

13. Chinese Society of Cardiology of Chinese Medical A, Cardiovascular Committee of Chinese Association of Rehabilitation M, Committee of Cardio-Cerebral-Vascular Diseases of Gerontological Society of C. [Chinese experts consensus on cardiac rehabilitation/secondary prevention for coronary artery disease]. Zhonghua Xin Xue Guan Bing Za Zhi. 2013;41(4):267-275.

14. Smith MC, Wrobel JP. Epidemiology and clinical impact of major comorbidities in patients with COPD. Int J Chron Obstruct Pulmon Dis. 2014;9:871-888. doi:10.2147/COPD
15. Young J, Donahue M, Farquhar M, Simpson C, Rocker G. Using opioids to treat dyspnea in advanced COPD: attitudes and experiences of family physicians and respiratory therapists. Can Fam Physician. 2012;58(7):e401-e407.

16. Oliveira AS, Munha J, Bugalho A, Guimaraes M, Reis G, Marques A. Identification and assessment of COPD exacerbations. Pulmonology. 2017.

17. Vogelmeier CF, Criner GJ, Martinez FJ, et al. Global strategy for the diagnosis, management, and prevention of chronic obstructive lung disease 2017 report. GOLD executive summary. Am J Respir Crit Care Med. 2017;195(5):557-582. doi:10.1164/rccm.201701-0218PP

18. Melin M, Montelius A, Ryden L, Gonon A, Hagerman I, Rullman E. Effects of enhanced external counterpulsation on skeletal muscle gene expression in patients with severe heart failure. Clin Physiol Funct Imaging. 2018;38(1):118-127. doi:10.1111/cpf.12392

19. Rampengan SH, Prihartono J, Siagian M, Immanuel S. The effect of enhanced external counterpulsation therapy and improvement of functional capacity in chronic heart failure patients: a randomized clinical trial. Acta Med Indones. 2015;47(4):275-282.

20. Tecson KM, Silver MA, Brune SD, et al. Impact of enhanced external counterpulsation on heart failure rehospitalization in patients with ischemic cardiomyopathy. Am J Cardiol. 2016;117(6):901-905. doi:10.1016/j.amjcard.2015.12.024

21. O'Donnell DE, Elbehairy AF, Berton DC, Domnik NJ, Neder JA. Advances in the evaluation of respiratory pathophysiology during exercise in chronic lung diseases. Front Physiol. 2017;8:82.

22. Valenzuela PL, Sanchez-Martinez G, Torrontegi E, Montalvo Z, Lucia A, de la Villa P. Enhanced external counterpulsation and short-term recovery from high-intensity interval training. Int $J$ Sports Physiol Perform. 2018;13(8):1100-1106. doi:10.1123/ijspp.2017-0792

23. Tian G, Xiong L, Lin W, et al. External counterpulsation reduces beat-to-beat blood pressure variability when augmenting blood pressure and cerebral blood flow in ischemic stroke. J Clin Neurol. 2016;12(3):308-315. doi:10.3988/jcn.2016.12.3.308

24. Xiong L, Tian G, Wang L, et al. External counterpulsation increases beat-to-beat heart rate variability in patients with ischemic stroke. J Stroke Cerebrovasc Dis. 2017;26(7):1487-1492. doi:10.1016/j. jstrokecerebrovasdis.2017.03.007

25. Ahlbom M, Hagerman I, Stahlberg M, et al. Increases in cardiac output and oxygen consumption during enhanced external counterpulsation. Heart Lung Circ. 2016;25(11):1133-1136. doi:10.1016/j.hlc.2016.04.013

26. Liu M. Effect of external counterpulsation on lung function in COPD. J Trop Med. 2016;16(6):776-778.

27. Gurovich AN, Braith RW. Enhanced external counterpulsation creates acute blood flow patterns responsible for improved flow-mediated dilation in humans. Hypertens Res. 2013;36 (4):297-305. doi:10.1038/hr.2012.169

28. Lin S, Liu M, Wu B, Hao Z, Yang J, Tao W. External counterpulsation for acute ischaemic stroke. Cochrane Database Syst Rev. 2012;1:Cd009264.

\section{Publish your work in this journal}

The International Journal of COPD is an international, peer-reviewed journal of therapeutics and pharmacology focusing on concise rapid reporting of clinical studies and reviews in COPD. Special focus is given to the pathophysiological processes underlying the disease, intervention programs, patient focused education, and self management protocols. This journal is indexed on PubMed Central, MedLine and CAS. The manuscript management system is completely online and includes a very quick and fair peer-review system, which is all easy to use. Visit http://www.dovepress.com/testimonials.php to read real quotes from published authors. 